\title{
When does the Moss-Harlow effect occur in discrimination reversal contexts?
}

\author{
HENRY A. CROSS and DAVID P. CANTRELL \\ Colorado State University, Ft. Collins, Colorado 80521
}

\begin{abstract}
An experiment tested for the Moss-Harlow effect in a discrimination reversal context by presenting 3to 5 -year-old children two-object discriminations followed by single-object information trials which indicated that a reversal was in effect, then by reversal test trials. The Moss-Harlow effect was not found, although it is normally found in preschoolers. This is consonant with other research with children using the reversal paradigm but not with research with monkeys. The divergent findings may result from species differences or the extent of the subjects' experience in the reversal situation. Researchers are advised against the use of the technique solely to familiarize subjects with test stimuli in Moss-Harlow research.
\end{abstract}

The Moss-Harlow (M-H) effect occurs when performance in a two-object discrimination is better following nonrewarded single-object information trials with the negative $(\mathrm{N})$ object than following rewarded information trials with the positive (P) object (Moss \& Harlow, 1947). The introduction of one stimulus later than the other, which is required by this procedure, has been suspected of confounding reward value learning with the effects of stimulus novelty (Berman, 1971; Cross \& Brown, 1965; Grabbe \& Campione, 1969; Reese, 1964). It now seems that "exploratory tendency" may be a more useful term than "novelty" (Cantrell \& Cross, Note 1), but the problem remains: when an information trial presents only one of two objects to the subject, response tendency to the other object may be affected.

However, if both objects were previously familiar to the subject, the effects of an exploratory tendency might be reduced or eliminated. One solution is to present both objects on the first trial and reward the chosen object or not according to the subject's assigned condition (Berman, 1971; Grabbe \& Campione, 1969), but the method removes the study from the single-object information trial $\mathrm{M}-\mathrm{H}$ paradigm. A reversal context has also been used to achieve object familiarity; the singleobject information trials are intercalated between two sets of two-object trials and indicate that a reversal will be in effect on the second set of trials.

The first experiment to use this format "was designed to explore the problem of what is learned in discrimination learning within the context of reversal learning (Cross \& Brown, 1965, p. 429)." The M-H effect was found, suggesting that in this case what was learned in the context of a reversal was the same as what was learned outside that context. This successful demonstration led to other uses of the technique in $\mathrm{M}-\mathrm{H}$ in-

This paper is from a thesis submitted by the second author to the graduate faculty of Colorado State University in partial fulfillment of the requirements for the degree of Master of Science. vestigations. Cross, Fickling, Carpenter \& Brown (1964) also found the M-H effect with monkey subjects. But child studies did not (Vaughter, 1968; Vaughter \& Cross, 1965). The Vaughter and Cross (1965) study was very similar in design to Cross \& Brown's original study but actually found better performance among preschool children following $P$ than $N$ information trials. The present experiment again replicated the Vaughter \& Cross study.

\section{METHOD}

\section{Subjects}

Twenty experimentally naive normal children were divided into two groups of 10, a young group with a mean CA of $3 ; 8$ (range: $2 ; 11-4 ; 0$ ) and an old group with a mean CA of $5 ; 5$ (range: $5 ; 2-6 ; 0)$. The were from predominantly low or lowermiddle socioeconomic strata.

\section{Apparatus}

A Wisconsin General Test Apparatus (WGTA) designed for use with children and similar to one described in Olson, Cross, and Vaughter (1966) was used. Forty multidimensional stimuli mounted on wooden bases were randomly grouped into 20 pairs.

\section{Procedure}

The child was conducted to the experimental room, seated at the WGTA, and asked if he liked candy. After the never-failing positive response, the experimenter said, "Well, this is a game called 'find the candy.' The first time it's very easy." The formboard was advanced toward the child with an M\&M candy in the center foodwell. The experimenter then said, "Did you find the candy? ... Good. That was easy. But now I'm going to hide the candy, and you have to guess which thing it's under. But each time you can only look under one-you have to guess which one the candy is under and then just pick up that one." The formboard was then extended, and the problem began.

Each subject received four problems, one from each of the four conditions, on each of 5 days, for a total of 20 problems. In all conditions, the subject first received 12 two-object discrimination trials. These were followed by four single-object center-well information trials, which indicated that a reversal was in effect, and which defined the experimental conditions, then by six reversal trials. In the $P$ condition, the subject received four rewarded information trials to the previously 
incorrect object, and in the $\mathrm{N}$ condition the subject received four nonrewarded trials to the previously correct object. A Mix condition gave two $\mathrm{P}$ and two $\mathrm{N}$ trials, and a No condition passed from discrimination to reversal trials without pause or warning.

The sequences of two $\mathrm{P}$ and two $\mathrm{N}$ trials in the Mix condition were randomly selected from the six possible sequences, with the restriction that no subject receive the same sequence twice. Random selections of six-trial left-right sequences were made from the eight equal left-right sequences described in Harlow (1950), with three selections providing the object-position determinations for the 18 two-object trials of one problem.

The same pairs of objects were used in the same sequence for all subjects. As the order of presentation of conditions was randomly determined within each day for each subject, the condition-object combinations varied, although the same four pairs were used on the same day's testing for all subjects. This method has been used by Leary (1956).

\section{RESULTS}

Two subjects were dropped because of prolonged absence, three "didn't want to play any more" and one responded exclusively on the basis of position. A splitplot analysis of variance of the number of correct responses was conducted. There was one between variable, the two levels of age, and two within variables, the four conditions and the six trials.

Conditions differed significantly, $F(3,54)=7.77$, $\mathrm{p}<.0005$. Tukey's HSD was used, at the .05 level, to test differences among the condition means, and showed the Mix, $N$, and $P$ conditions to be superior to the No condition. The Mix, $\mathbf{N}$, and $\mathbf{P}$ conditions did not differ. No age effects were found.

The significant trials effect, $F(5,90)=30.87$, $\mathrm{p}<.0005$, reflected a low level of performance on Trial 1, a considerable improvement on Trial 2, and no subsequent improvement. Tukey's HSD showed performance to be lower on Trial 1 than on all others, and all others to be statistically equal. Figure 1 shows the nature of the two significant effects.

\section{DISCUSSION}

The M-H effect was not found. Thus, two studies have found the $\mathrm{M}-\mathrm{H}$ effect in a reversal context, three have not. The two that did both used monkeys, the others used preschoolers.

But the different results may also have resulted from an experience variable. Information trials in the reversal context carry a substantially different and probably more complex message in the reversal context than in the usual $\mathrm{M}-\mathrm{H}$ situation, and it may be that only more experienced subjects can use the information. In the Cross and Brown study, condition differences did not emerge in the first block of 16 problems, and the experiment included a total of 64 problems. Cross et al. used the same, now-sophisticated, subjects. The lengths of the three human studies have all been comparable to the first trial block in Cross and Brown (1965): 16 problems in Vaughter and Cross (1965), 24 problems in Vaughter (1968) and 20 problems in the present experiment.

Knowledge of which variable, species or experience, is critical must await further research. In the meantime, research-

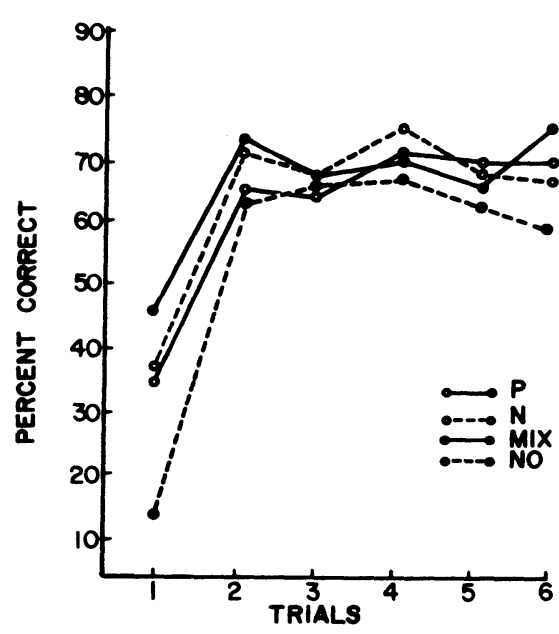

Figure 1. Percent of correct responses.

ers may be well-advised to avoid the use of the reversal context solely as a way to create or equate object familiarity in $\mathrm{M}-\mathrm{H}$ research.

\section{REFERENCE NOTE}

1. Cantrell, D. P., \& Cross, H. A. Appearance of the Moss-Harlow effect with stimuli equated for novelty. Submitted for publication, 1975 .

\section{REFERENCES}

Berman, P. W. Stimulus novelty as a variable in children's win-stay, lose-shift discrimination learning set. Child Development, 1971, 42, 1591-1595.

Cross, H. A., \& Brown, L. T. Discrimination reversal learning in squirrel monkeys as a function of number of acquisition trials and prereversal experience. Journal of Comparative and Physiological Psychology, 1965, 59, 429-431.

Cross, H. A., Fickling, R. M., Carpenter, J. B., \& BRown, L. T. Discrimination reversal performance in squirrel monkeys as a function of prereversal experience and overlearning. Psychonomic Science, 1964, 1, 353-354.

GrabBe, W., \& Campione, J. C. Novelty interpretation of the Moss-Harlow effect in preschool children. Child Development, 1969, 40, 1077-1084.

Harlow, H. F. Analysis of discrimination learning by monkeys. Journal of Experimental Psychology, 1950, 40, 26-39.

LEARY, R. W. The rewarded, the nonrewarded, the chosen and the unchosen. Psychological Reports, 1956, 2, 91-97.

Moss, E. M., \& HaRLow, H. F. Role of reward in discrimination learning in monkeys. Journal of Comparative and Physiological Psychology, 1947, 40, 333-342.

Olson, B. A., Cross, H. A., \& Vaughter, R. M. Apparatus note: A modified WGTA for children. Psychonomic Science, 1966, 5, 319.

ReESE, H. W. Discrimination learning set in rhesus monkeys. Psychological Bulletin, 1964, 61, 321-340.

VAUGHTER, R. M. Analysis of discrimination reversal learning in children. Psychonomic Science, 1968, 11, 49-50.

Vaughter, R. M., \& Cross, H. A. Discrimination reversal performance in children as a function of prereversal experience and overlearning. Psychonomic Science, 1965, 2, 363-364.

(Received for publication July 2, 1975.) 